\title{
JMT Based Performance Evaluation of Network for Dynamic Service Time Distribution
}

\author{
J.Ann Roseela ${ }^{1}$, Dr. T.Godhavari ${ }^{2}$, Dr. T.Vimala ${ }^{3}$ \\ ${ }^{1}$ Research Scholar, ECE Department, Dr.M.G.R.Educational and Research Institute, Chennai. \\ Email: annroseelaramu@yahoo.com \\ ${ }^{2}$ Professor \& Head, ECE Department, Dr.M.G.R.Educational and Research Institute, Chennai. \\ Email:t.godhavari@gmail.com \\ ${ }^{3}$ Associate Professor, ECE Department, Dr.M.G.R.Educational and Research Institute, Chennai. \\ Email:vim74@yahoo.com
}

\begin{abstract}
In this paper queuing models in networks using JMT is studied. The input and output contention for different traffic flow patterns like Poisson process, Burst (MMPP2) process etc...is described in demonstrated and simulated in this paper. The developed configuring consists of a workstation sending requests over an Intranet which is composed of Web servers, Application Server and Database Server. The application server in the Intranet further connects itself to a remote server using Ethernet connection. The obtained confidence interval is compared with the requested confidence interval.
\end{abstract}

Keyword - Poisson process, Web servers, Application Server, Database Server,JMT (Java Modeling Tool)

\section{INTRODUCTION}

In this work, the performance of the designed model is studied for different service time distribution namely as Burst (MMPP2), Constant, Erlang, Exponential, Gamma, Hyper-exponential, Normal, Pareto, Poisson, Replayer, Student T and uniform are used.This paper investigates the queuing models in networks using JMT for different service time distributions JMT is an open source simulation tool to study the queuing models in the network. Java programming language is used in the JMT tool.Network with a communication path between nodes not exist refer to delay tolerant networks, they communicate either by already

defined routes or through other nodes .when the network extents over long distance ,choosing right queuing discipline and the adequate queue length with different traffic patterns, it is important to select a queuing length that is suitable for your environment .Configuring a queue length that is too shallow could easily transmit traffic into the network results in discarded packets.Queuing management is one of the fundamental techniques, choosing the correct implementation can contribute to your network operating optimally

\section{RELATED WORKS}

Paul Lettieri and Mani B. Srivastava (1998) proposed an adaptive frame length control for improving wireless link throughput, range and energy efficiency. The variable frame length in terms of users increases the throughput,effective transmission range, and transmitter power for wireless links. The impact of the length of the MAC layer frames on the performance of a wireless link is studied. If the channel condition is not stable, then the MTU (Maximum Transmission Unit) parameter is varied.

MingyueJi et al., (2014) study the throughput scaling laws of wireless networks with caching and asynchronous content reuse, contrasting the device to device (D2D) approach with conventional approach based on combinatorial cache design and network coded transmission from the cellular base station only. A realistic model of a single cell system with ' $n$ ' users with cache memory of ' $M$ ' files and independent streaming requests is designed. Performance of the realistic system for various schemes is reviewed.

Juan Luo et al., (2015) uses data relay in 1-D queue network to increases the lifetime of the network and decrease the energy consumption. In Energy equivalent node (EEN), according to the opportunistic routing theory, relay nodes are selected to virtually derive the optimal transmission distance for energy saving and maximizing the lifetime of whole network. The interference among the generated signals of each node is ignored.

E.M. Malathy and Dr. VijayalakshmiMuthuswamy (2016) utilize the tandem queuing model for wireless next generation network and facilitate zero level failure of vertical handover calls in interoperable network environment. The proposed algorithm enables mobile user roaming across different networks while keeping connected and not disturbing the ongoing sessions 
Chyi-Ren Dow et al., (2016) proposed routing management system by using location based services and zone queuing techniques on Internet of Things (IoT). A queuing table is used in the control center and neighbor tables are used in RSUs for zone queuing establishment.

\section{SERViCE Time Distribution}

In this work, the performance of the designed model is studied for different service time distribution namely as Burst (MMPP2), Constant, Erlang, Exponential, Gamma, Hyper-exponential, Normal, Pareto, Poisson, Replayer, Student T and uniform are used. The description of the various service time distributions is shown in table 1.

TABLE I. DESCRIPTION OF SERVICE TIME DISTRIBUTION

\begin{tabular}{|c|c|}
\hline Service time distribution & Description \\
\hline $\begin{array}{c}\text { Burst (MMPP2) } \\
\text { distribution }\end{array}$ & $\begin{array}{c}\text { Jumps between two states (i.e. state with slow inter } \\
\text { arrival and state with fast arrival time) }\end{array}$ \\
\hline Poisson distribution & Number of request for a time interval \\
\hline Uniform distribution & Constant probability for a time interval \\
\hline Exponential distribution & $\begin{array}{c}\text { Time interval for consecutive request is defined as } \\
\text { exponential random variable }\end{array}$ \\
\hline
\end{tabular}

\section{DESIGNED MODEL}

The model consists source station named as request from users, workstation CPU, webserver 1, webserver 2, application server, database server and remote application server are the queuing station, routing station named as load balancer, sink station named as request committed and the delay station named as Ethernet cable.In designed model there are two finite capacity regions (FCR) namely intranet and Ethernet. The FCR structure allows to fix the maximum number of customers in a set of resources and also allows the priority scheduling. The designed model is shown in figure 1.

The workstation CPU, web server1, web server2, application server, database server and remote application server are consists a queue and one or more servers to perform the user requests. If both the webserver1 and webserver2 of the designed model are busy state while a new request send from the 'request from users' station, the arriving request queued and waits for some time to server get idle state. Based on 'First come First serve' queuing discipline user request is served after a server get idle state. Sum of service time and queuing time is called as the response time of queuing stations. In this work, number of server in the queuing station is specified as' ${ }^{\prime} 1$ '. The fraction of time in which a single server is busy (utilization) $U$ is given by $U=\lambda S$, and in a station with ' $\mathrm{m}$ ' servers the utilization of separate server is given by $U=\lambda \mathrm{S} / \mathrm{m}$. If the maximum number of request (customer) is reached, the remaining request is rejected by using the 'drop rule'. Ethernet cable acts a delay station. Some amount of delay is applied to the user request by using the Ethernet cable. The service time $\left(\mathrm{s}_{\mathrm{i}}\right)$ of the Ethernet cable same as the delay time $\left(\mathrm{d}_{\mathrm{i}}\right)$ of the station.

\section{CUSTOMER CLASSES}

Customer classes are used to define the customer behavior and characteristics, such as the type (closed or open), the size of the customer population (for closed classes) or the interarrival time distribution (for open classes). A class that has class switch as reference station cannot be generated by a source station is called as open classes. If a class switch is in the model, then all classes must have the same reference station is called as closed classes. In this work, customer type is used as open with interarrival time distribution as Poisson with mean value of 0.5 .

A. Properties of the components in designed model

The properties of the components in designed model are shown in table 2. The properties of the FCR region is shown in table 3.

TABLE 2. CAPACITY OF FCR REGION

\begin{tabular}{|c|c|}
\hline FCR region & Region capacity \\
\hline Intranet (FCR region 1 ) & Infinite \\
\hline Ethernet (FCR region 2 ) & Infinite \\
\hline
\end{tabular}


TABLE 3. PROPERTIES OF THE COMPONENTS IN QUEUING MODE

\begin{tabular}{|l|l|l|l|l|l|l|}
\hline Components & $\begin{array}{l}\text { Queuing } \\
\text { capacity }\end{array}$ & $\begin{array}{l}\text { Queue } \\
\text { policy }\end{array}$ & $\begin{array}{l}\text { Service station } \\
\text { strategy }\end{array}$ & $\begin{array}{l}\text { Service time } \\
\text { distribution }\end{array}$ & $\begin{array}{l}\text { Routing } \\
\text { strategy }\end{array}$ & $\begin{array}{l}\text { Number of } \\
\text { customers }\end{array}$ \\
\hline $\begin{array}{l}\text { Workstation } \\
\text { CPU }\end{array}$ & Infinite & FCFS & $\begin{array}{l}\text { Load } \\
\text { independent }\end{array}$ & Burst MMPP2 & Random & - \\
\hline Web server 1 & Infinite & FCFS & $\begin{array}{l}\text { Load } \\
\text { independent }\end{array}$ & $\begin{array}{l}\text { Poisson with } \\
\text { mean value 0.5 }\end{array}$ & Random & - \\
\hline Web server 2 & Infinite & FCFS & $\begin{array}{l}\text { Load } \\
\text { independent }\end{array}$ & $\begin{array}{l}\text { Poisson with } \\
\text { mean value 0.5 }\end{array}$ & Random & - \\
\hline $\begin{array}{l}\text { Remote } \\
\text { application } \\
\text { server }\end{array}$ & Infinite & FCFS & $\begin{array}{l}\text { Load } \\
\text { independent }\end{array}$ & $\begin{array}{l}\text { Poisson with } \\
\text { mean value 0.5 }\end{array}$ & Random & - \\
\hline $\begin{array}{l}\text { Application } \\
\text { server }\end{array}$ & Infinite & $\begin{array}{l}\text { FCFS with } \\
\text { drop rule }\end{array}$ & $\begin{array}{l}\text { Load } \\
\text { independent }\end{array}$ & $\begin{array}{l}\text { Poisson with } \\
\text { mean value 0.5 }\end{array}$ & Random & 1000 \\
\hline $\begin{array}{l}\text { Database } \\
\text { server }\end{array}$ & Infinite & $\begin{array}{l}\text { FCFS with } \\
\text { drop rule }\end{array}$ & $\begin{array}{l}\text { Load } \\
\text { independent }\end{array}$ & $\begin{array}{l}\text { Poisson with } \\
\text { mean value 0.5 }\end{array}$ & Random & 1000 \\
\hline Load balancer & - & - & - & - & Random & - \\
\hline $\begin{array}{l}\text { Ethernet cable } \\
\text { Request from }\end{array}$ & - & - & $\begin{array}{l}\text { Load } \\
\text { independent }\end{array}$ & $\begin{array}{l}\text { Poisson with } \\
\text { mean value 0.5 }\end{array}$ & Random & - \\
\hline $\begin{array}{l}\text { Request } \\
\text { committed }\end{array}$ & - & - & - & Random & - \\
\hline
\end{tabular}

\section{JMT TOOL}

JMT is an open source simulation tool to study the queuing models in the network. Java programming language is used in the JMT tool.

\section{A. Simulation setup}

In JMT (Java Modeling Tool), the model is designed. And the components parameters are defined.The transient length, maximum error request, maximum number of samples and confidence intervals are defined before the simulation process because the results affected by the these factors. After the simulation completion, the selected performance index (in this work system response time, system throughput and system drop rate) are displayed.

The results are obtained for different service time distribution is shown in table 4.

TABLE 4. SIMULATED RESULTS

\begin{tabular}{|c|c|c|c|c|}
\hline $\begin{array}{c}\text { Workstation CPU } \\
\text { service time } \\
\text { distribution }\end{array}$ & $\begin{array}{c}\text { Other stations } \\
\text { service time } \\
\text { distribution }\end{array}$ & $\begin{array}{c}\text { Average value } \\
\text { of system } \\
\text { response time }\end{array}$ & $\begin{array}{c}\text { Average value } \\
\text { of system } \\
\text { throughput }\end{array}$ & $\begin{array}{c}\text { Average value } \\
\text { of system drop } \\
\text { rate }\end{array}$ \\
\hline Poisson & Poisson & 1420.249 & 0.998 & 1.005 \\
\hline Uniform & Poisson & 948.072 & 0.999 & 0.985 \\
\hline Burst (MMPP2) & Poisson & $2.91 \mathrm{E} 4$ & 0.604 & 0.380 \\
\hline Exponential & Poisson & $1.05 \mathrm{E} 5$ & 1.000 & 0.380 \\
\hline
\end{tabular}

The system response time, system throughput and the system drop rate for four cases of Service Time Distribution is shown in figure 1 to figure 12. The green tick indicates the measured confidence interval of the performance index does not exit the user defined value. If the red tick appeared, it indicates the measured confidence interval of the performance index exits the user defined value.

\section{B. Case i:}

Workstation CPU service time distribution: Poisson

Other stations service time distribution: Poisson 


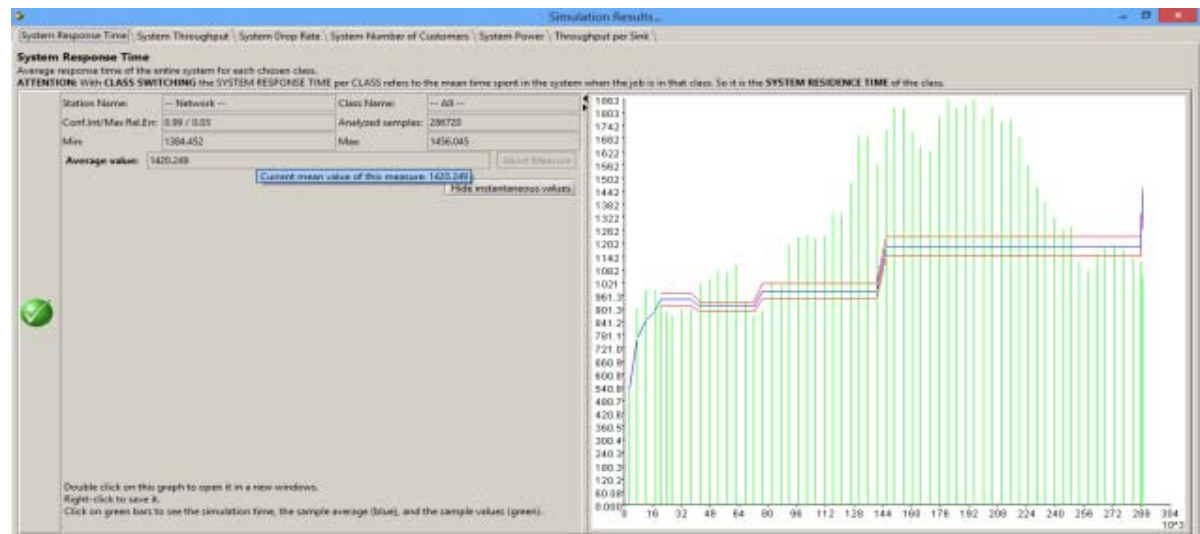

Fig.1 System Response Time

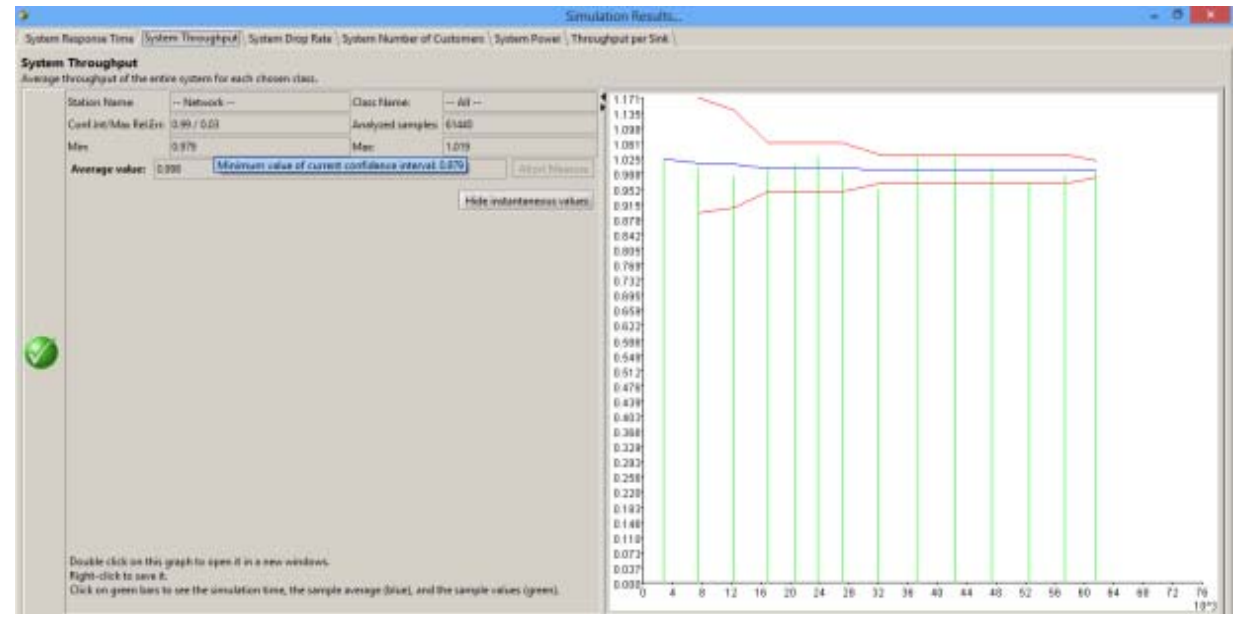

Fig.2 System Throughput

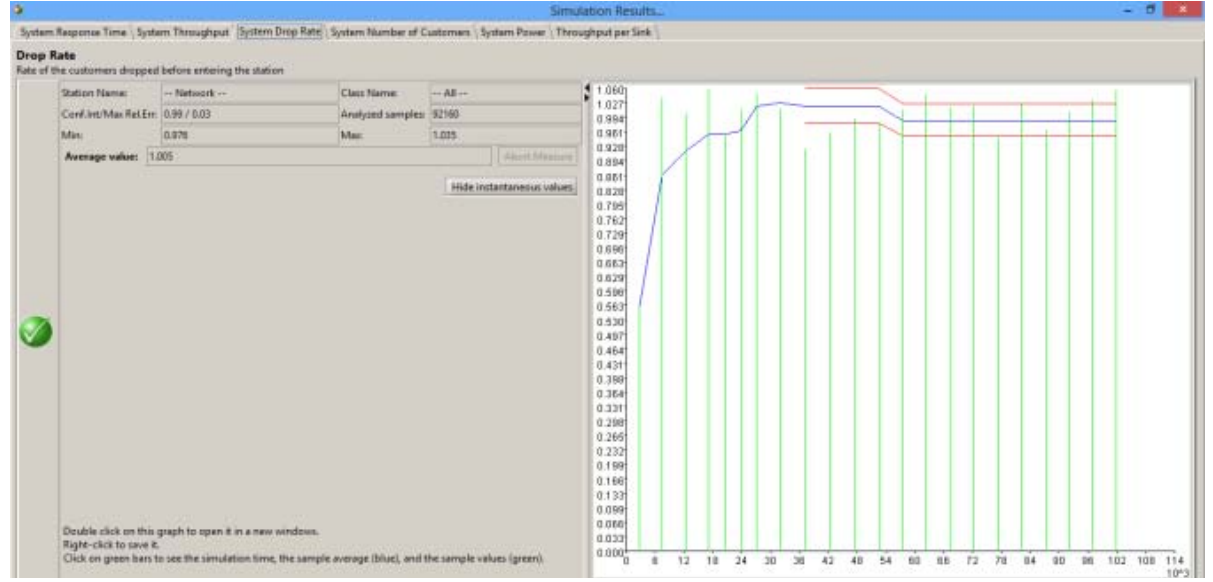

Fig.3 System Drop Rate

\section{Case ii:}

Workstation CPU service time distribution: Uniform

Other stations service time distribution: Poisson 


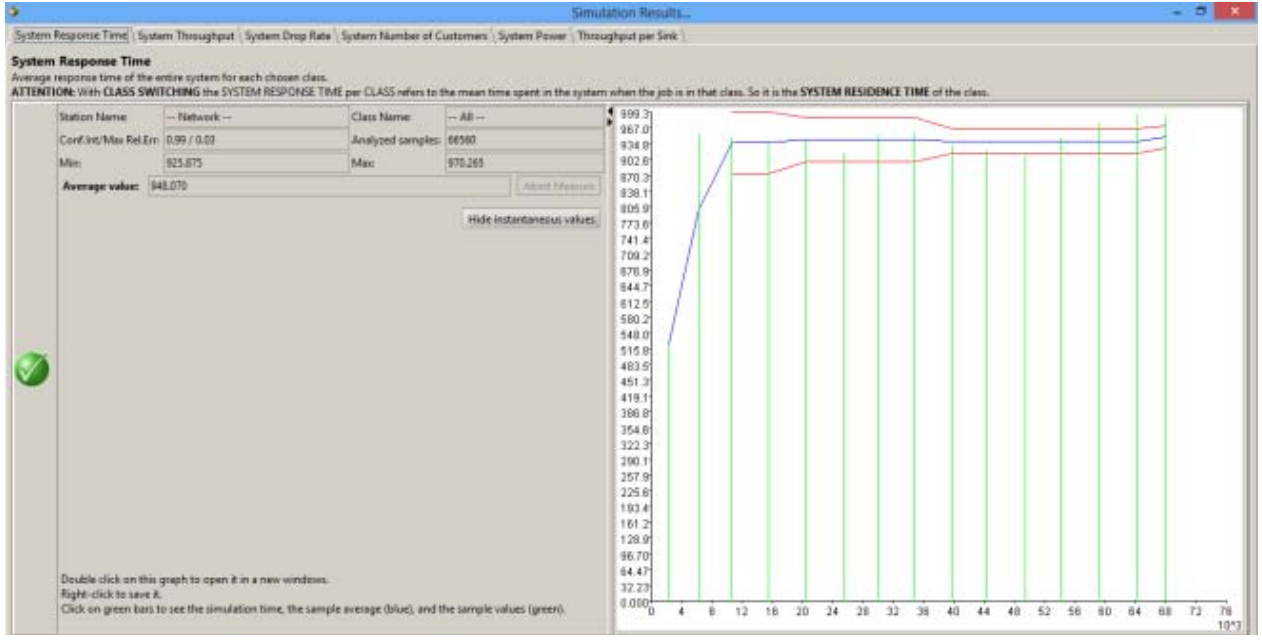

Fig.4 System Response Time

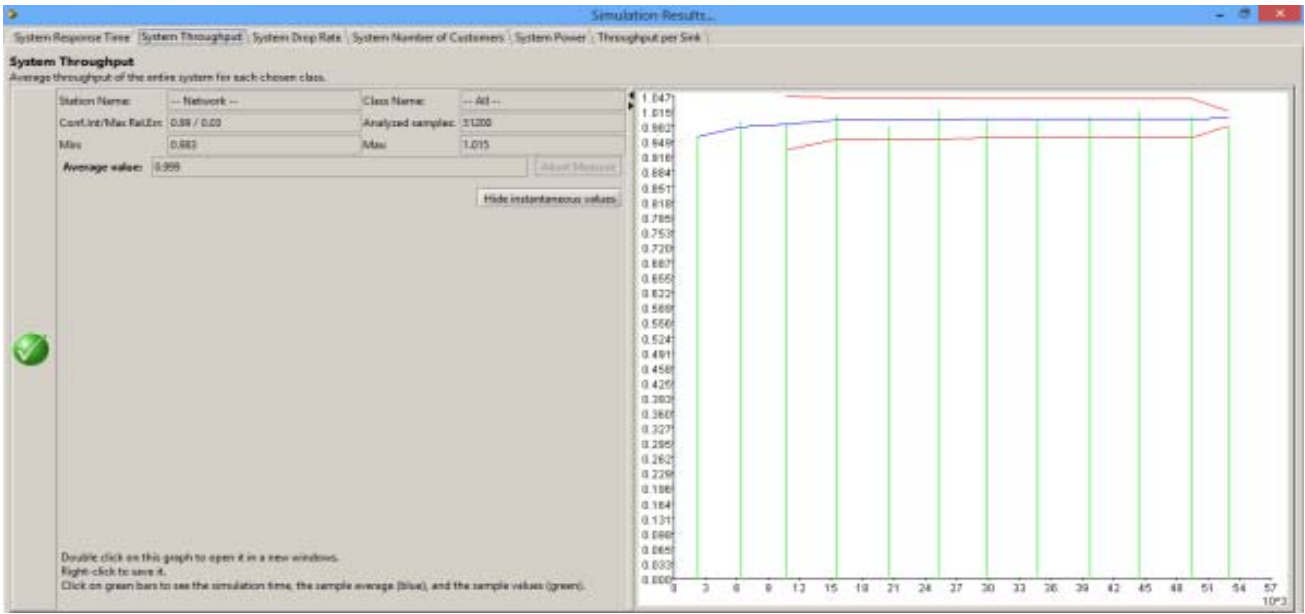

Fig.5 System Throughput

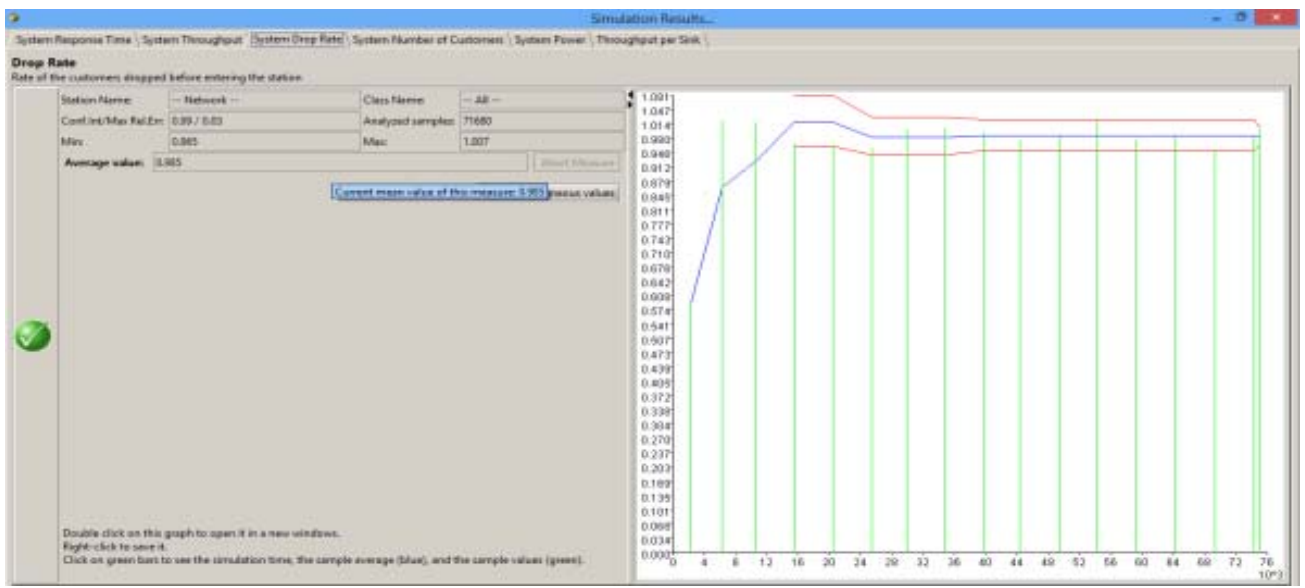

Fig.6 System Drop rate

D. Case iii:

Workstation CPU service time distribution: Burst (MMPP2)

Other stations service time distribution: Poisson 


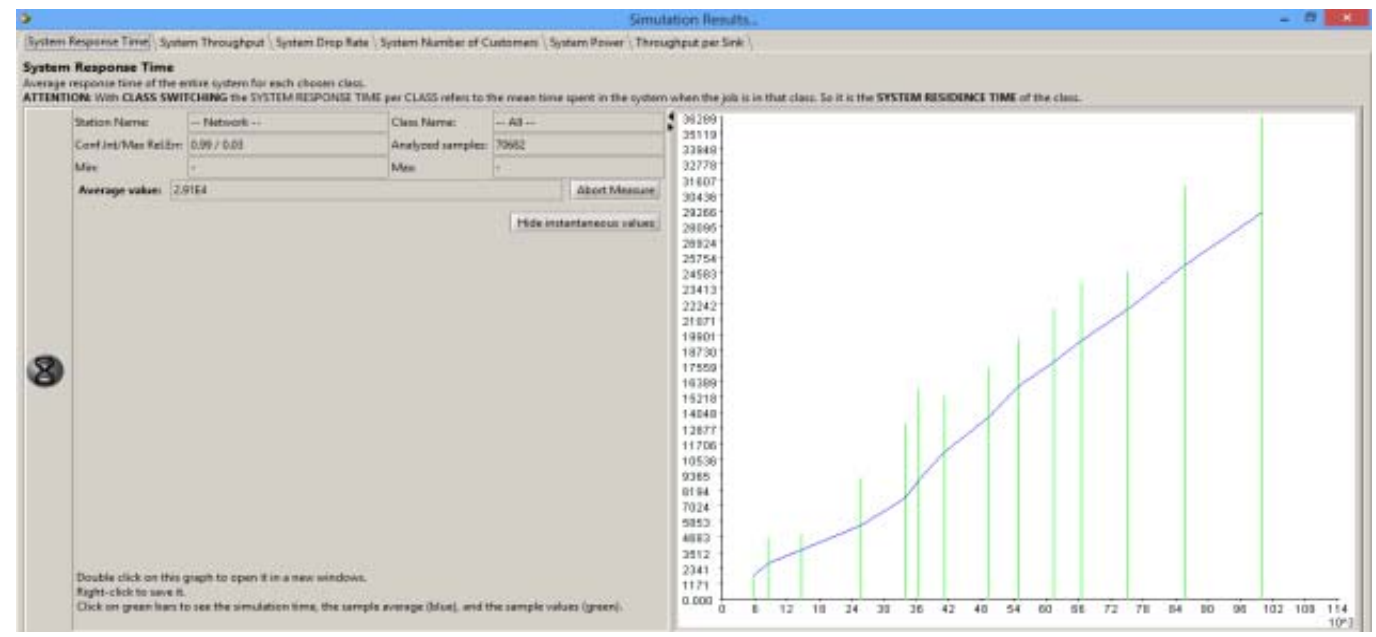

Fig.7 System Response Time

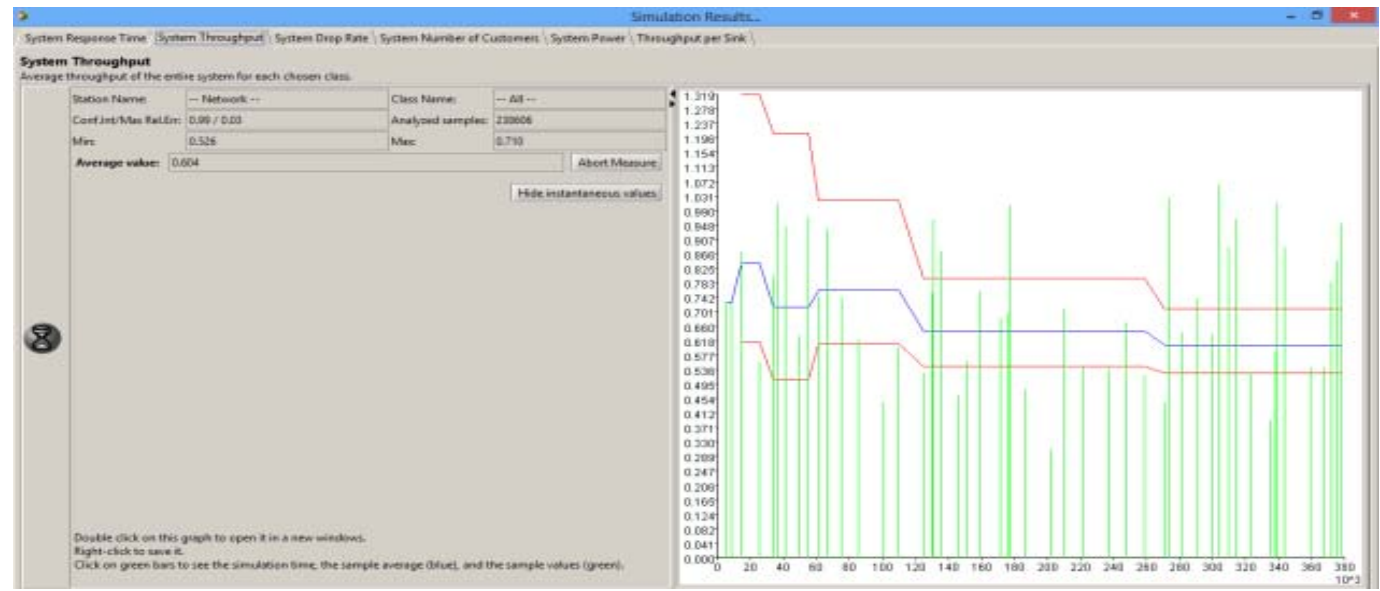

Fig.8 System Throughput

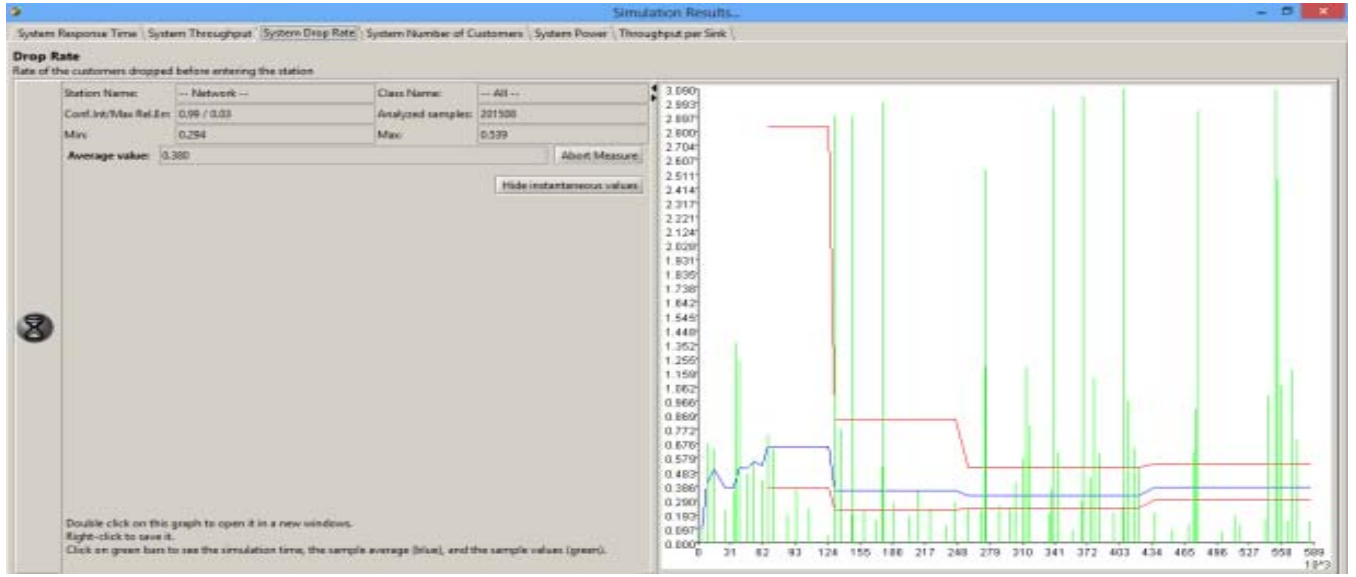

Fig. 9 system drop rate

E. Case iv:

Workstation CPU service time distribution: Exponential

Other stations service time distribution: Poisson 


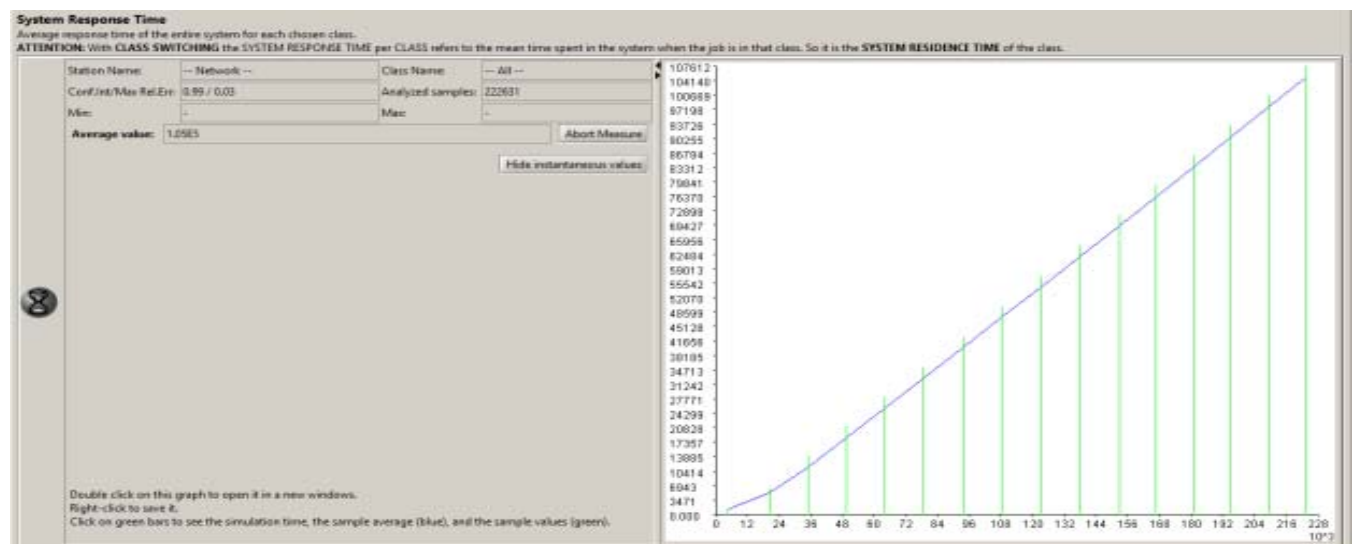

Fig. 10 System Response Time

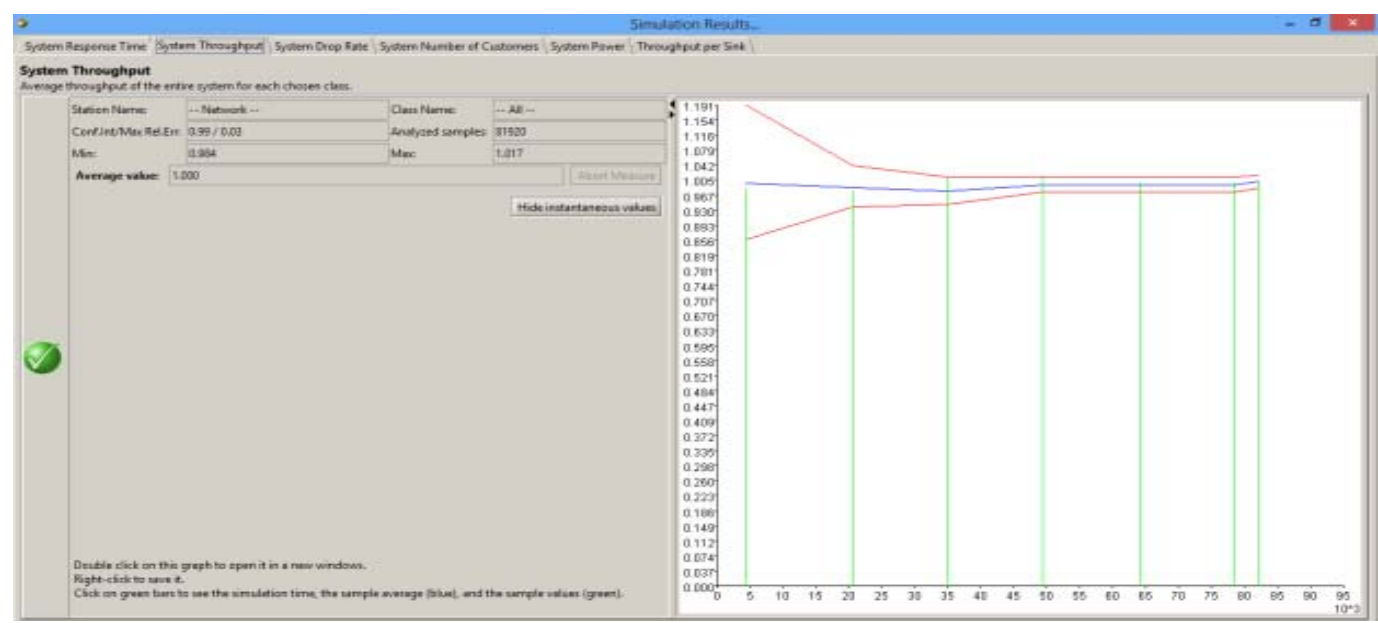

Fig. 11 System throughput

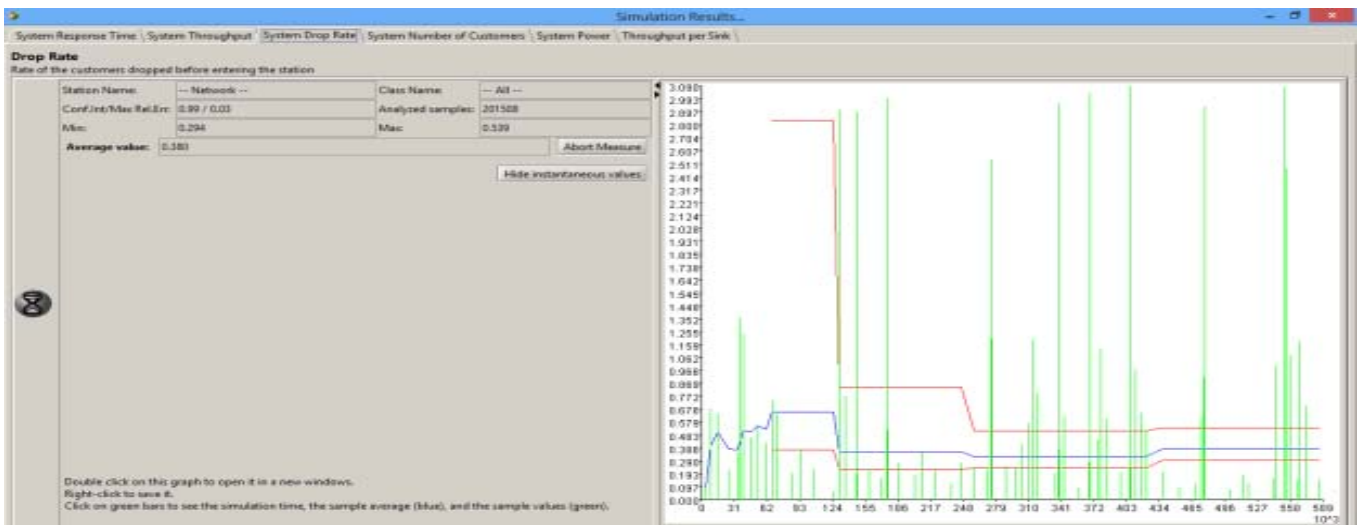

Fig. 12 System drop rate

In figure 2 to figure 13, the confidence interval, maximum relative error, analyzed samples, minimum/maximum value of the performance index and the average value of the all performance index also displayed. The $\mathrm{x}$-axis of the simulation results is the simulation time. In figure 14, the red lines in simulation results are the values in the final set of values. The green bar indicates the mean value of the performance index in the last interval. The transient's values are discarded in the computation. The mean and instantaneous values are shown in figure 8 . 


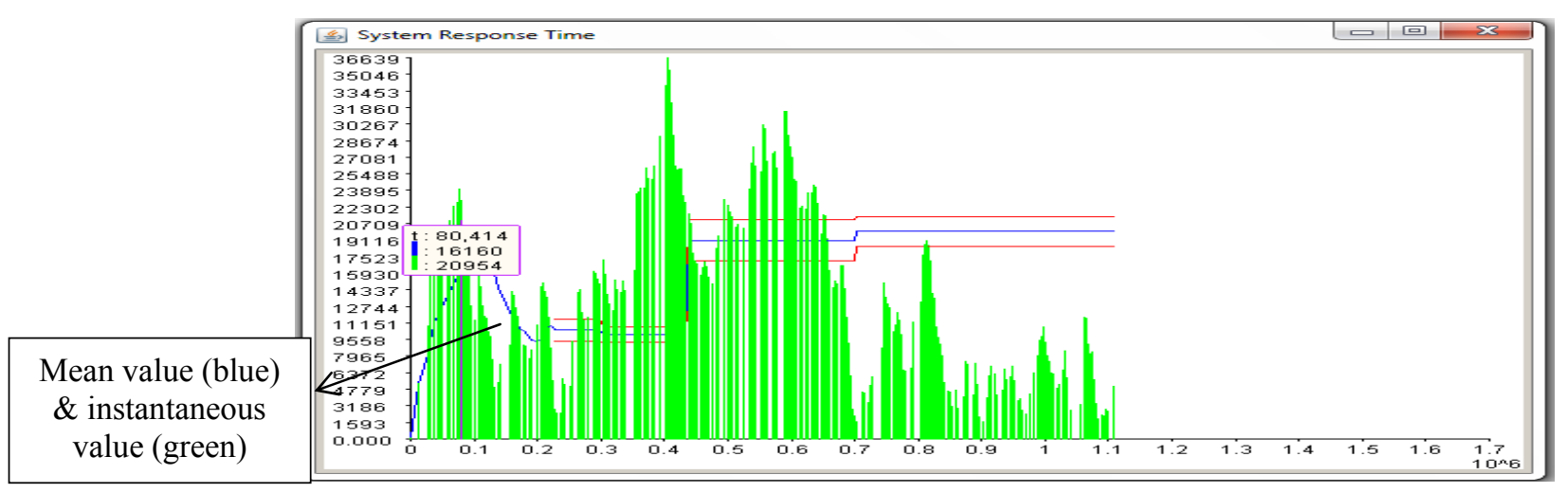

Fig. 13Mean value and instantaneous value

\section{CONCLUSION}

The performance of the network model is studied for load independent and load dependent strategies. The complex traffic pattern and service times are simulated for the designed network model. The performance of the network measured for dynamic the number of user. In this paper the measured performance indices along with their confidence intervals is displayed as graphical manner. The transient detection and discarding of transient is done in the paper.

\section{REFERENCES}

[1] Paul Lettieri and Mani B. Srivastava, "Adaptive Frame Length Control for Improving Wireless Link Throughput, Range, and Energy Efficiency", INFOCOM '98. Seventeenth Annual Joint Conference of the IEEE Computer and Communications Societies. Proceedings. IEEE (Volume:2)

[2] MingyueJi, Giuseppe Caire and Andreas F. Molisch, "Wireless Device-to-Device Caching Networks: Basic Principles and System Performance", IEEE Journal on Selected Areas in Communications (Volume:34, Issue: 1)

[3] Juan Luo, Jinyu Hu, Di Wu, and Renfa Li, "Opportunistic Routing Algorithm for Relay Node Selection in Wireless Sensor Networks", IEEE TRANSACTIONS ON INDUSTRIAL INFORMATICS, VOL. 11, NO. 1, FEBRUARY 2015.

[4] Chyi-Ren Dow, Duc-Binh Nguyen, Shr-ChenWang, Shiow-Fen Hwang, and Ming Fong Tsai, "A Geo-Aware Taxi Carrying Management System by Using Location Based Services and Zone Queuing Techniques on Internet of Things", Mobile Information Systems Volume 2016 (2016), Article ID 9817374, 10 page

[5] E.M. Malathy and Dr. VijayalakshmiMuthuswamy, "VERTICAL HANDOVER FACILITATION THROUGH QUEUING MODEL IN HETEROGENEOUS WIRELESS NETWORK”, International Journal of Advanced Engineering Technology, Vol. VII/Issue I/Jan.March.,2016/346-348

[6] Muhammad FaheemMushtaq, SaleemUllah, M. AbubakarSiddique, ShahzadaKhurram and NajiaSaher, "Improving Queuing System Throughput Using Distributed Mean Value Analysis to Control Network Congestion", scientific research publishing, Vol.7 No.1, February 2015

[7] Nathan Hanford, Vishal Ahuja, Matthew Farrens, DipakGhosal, Mehmet Balman, Eric Pouyoul and Brian Tierney, "Improving network performance on multicore systems: Impact of core affinities on high throughput flows", Elsevier Volume 56, March 2016, Pages 277-283.

[8] NICHOLAS BAMBOS and GEORGE MICHAILIDIS, "Queuing Networks of Random Link Topology: Stationary Dynamics of Maximal

[9] Throughput Schedules", springer queuing systems May 2005, Volume 50, Issue 1, pp. 5-52.

[10] Bertsimas, D. and Mourtzinou, G. (1997) MulticalssQueueing System in Heavy Traffic: An Asymptotic Approach Based on Distributional and Conversational Laws. Operations Research, 45, 470-487. http://dx.doi.org/10.1287/opre.45.3.470

[11] M. Ji, G. Caire, and A.F. Molisch, "Optimal throughput-outage trade-off in wireless one-hop caching networks," arXivpreprint arXiv:1302.2168, 2013.

[12] M. Franceschetti, M. D. Migliore, and P. Minero, "The capacity of wireless networks: Information-theoretic and physical limits," Information Theory, IEEE Transactions on, vol. 55, no. 8, pp. 3413-3424, 2009.

[13] P. Bhagwat, P. Bhattacharya, A. Krishna, and S. Tripathi, "Enhancing throughput over wireless LANs using Channel State Dependent Packet Scheduling," Proceedings of IEEE Infocom 1996, vol. 3, pp. 1133-1140, March 1996.

[14] C. Fragouli, V. Sivaraman, and M. B. Srivastava, "Controlled Multimedia Wireless Link Sharing via Enhanced Class-Based Queuing with Channel-State-Dependent Packet Scheduling," Private communications.

[15] H. Balakrishnan, S. Seshan, E. Amir, R.H.Katz, "Improving TCP/IP Performance over Wireless Networks," In Proceedings of the First ACM Conference on Mobile Computing and Networking 1995 (MobiCom’95), November 1995.

\section{AUTHOR PROFILE}

J.Ann Roseela, Research Scholar, ECE Department, Dr.M.G.R.Educational and Research Institute, Chennai. Email: annroseelaramu@yahoo.com

Dr. T.Godhavari, Professor \& Head, ECE Department, Dr.M.G.R.Educational and Research Institute, Chennai. Email:t.godhavari@gmail.com

Dr. T.Vimala, Associate Professor, ECE Department, Dr.M.G.R.Educational and Research Institute, Chennai. Email:vim74@yahoo.com 